\title{
Numerical Studies on the Stiffness of Arc Elliptical Cross-section Helical Spring Subjected to Circumference Force
}

\author{
Yuan WANG*, Qingchun WANG**, Zehao SU*** \\ *School of Technology, Beijing Forestry University, NO.35 Qinghua East Road, Haidian District,100083 Beijing, China, \\ E-mail:645044350@qq.com \\ **School of Technology, Beijing Forestry University, NO.35 Qinghua East Road, Haidian District,100083 Beijing, China, \\ E-mail: wangqingchun@bjfu.edu.cn (Corresponding author) \\ ***School of Technology, Beijing Forestry University, NO.35 Qinghua East Road, Haidian District,100083 Beijing, \\ China, E-mail: suzehao4083@foxmail.com
}

crossref http://dx.doi.org/10.5755/j02.mech.24907

\section{Introduction}

As a common mechanical part, many varieties of springs are widely used in buffering or vibration damping, mechanical energy storage, control motion, force measuring device, etc. Its performance will directly affect the performance of mechanical equipment. Over the past years, the helical springs subjected to static load [1] have been investigated by numerous studies, most of which focused on the circle-section springs [2, 3], with several concentrated on the elliptical-section [4], to say nothing of there are few researches pay attention on the arc helical springs [5]. Arc springs are mainly used to bear the circumferential force so their performance have big impacts on vehicle noise who are always appear in Dual Mass Flywheel and so on [6-10], therefore it is essential to study the stiffness which is influenced by spring index and parameters of the diameters, to make it more convenient to choose the proper size of arc spring to satisfy the stiffness and installation site.

The theoretical study of elliptical helical spring can be dated back to 1950s with Shiguma who has emphasized two prominent advantages of elliptical helical springs compared with circular wire helical springs that are[3]: 1)When the free height is the same, the elliptical section helical spring has a larger working stroke than the circular section common coil spring, which can save installation space; 2) The elliptical cross-section helical spring can make the cross-section stress distribution more uniform than the circular cross section and the elliptical section by selecting the appropriate cross-sectional aspect ratio, that is, the ratio of the long axis length to the short axis length, and thus can withstand greater stress and longer fatigue life. But he has not verified these two points by experiment data or stiffness formulae. Nagaya from Japan studied the cylindrical elliptical springs and put forward the stiffness formula. Wei Hu [10] improved the stiffness expression. And most significant was Gzal M's study for the cylindrical elliptical springs, he investigated the spring by purely formula derivation and got the formula proved by Finite Element Analysis method. In 21century there were some arc circular-section helical springs' stiffness were supposed.

Commonly various methods such as Finite Element Analysis [11], Fourier collocation [12] and boundary element method which can be used for exploring the stiffness of circular-section helical springs [13]. But these methods were not used for predicting the property of arc elliptical cross-section helical springs, nor other relevant studies have been uncovered its stiffness formula.

At present, the methods commonly used to study the stiffness of spring are analytical method [14], experimental method and finite element method [15]. The finite element method plays a significant role in the spring design because of its advantages of high efficiency, cost reduction and high accuracy [7]. In this paper, the existing theoretical formulae for cylindrical springs and elliptical cross-section helical springs were proposed firstly. Finite element analysis, multivariate statistical regression and experimental design methods were used to obtain the stiffness. Compared with the existing theoretical formulae, the error is in the scope of engineering application, which proves the effectiveness of the methods, the stiffness formula of the arc elliptical section spring is derived by the above method finally.

\section{Methods and materials}

\subsection{The variety of springs and the stiffness formulae}

In this section, the novelty method was proposed to verify the correctness of existing formulas of springs, it is a synthesis of finite element method, multivariate statistical regression method and experimental design method. In order to prevent confusing stiffness of springs type, Cylindrical helical springs with Circular-section subjected to axial load is substituted as C-C, Cylindrical helical springs with Elliptical circular-section subjected to axial load is substituted as C-E. In same way, A-C means Arc helical springs with Circular-section subjected to circumferential load, AE Means Arc helical springs with Elliptical circular-section subjected to circumferential load.

1) Cylindrical helical springs with circular-section subjected to axial load.

Cylindrical helical springs are the most common type of springs used in engineering applications. At present, some theoretical formulae for cylindrical helical spring stiffness have been proposed. Wahl [14] ignored the effect of pure shear on spring deformation, considering the axiallyloaded cylindrical helical spring as a uniform section beam, and obtained the common stiffness formula:

$$
K_{C-C}=\frac{G d^{4}}{8 D^{3} n},
$$

where: $K_{C-C}$ is the spring wire stiffness; $G$ is the shear modu- 
lus of the spring material; $d$ is the spring wire diameter; $D$ is the spring diameter; $n$ is the effective number of spring turns. This formula is suitable for the case where the spring helix angle $\alpha$ is small and the spring index $C=D / d$ is relatively large in which case the effect of pure shear is negligible compared with the influence of torque.

Mohazzabi [11] considered the case that the spring index is relatively small, and the stiffness formula is corrected with the form of pure torsion and pure shear effect addition:

$$
K_{C-C}=\frac{G d^{4}}{8 D^{3} n}\left[1+\frac{1}{2}\left(\frac{d}{D}\right)^{2}\right]^{-1}
$$

Ancker and Goodier [14] corrected the stiffness formula considering the effect of the helix angle and curvature:

$$
K_{C-C}=\frac{G d^{4}}{8 D^{3} n}\left[1-\frac{3}{16}\left(\frac{d}{D}\right)^{2}+1.27(\tan \alpha)^{2}\right]^{-1} .
$$

2) Arc helical circular cross-section springs subjected to circumference force.

Tao Chen [15] put forward the simply stiffness formula of arc helical circular cross-section springs subjected to circumference force as follow:

$$
K_{A-C}=\frac{G d^{4} R^{2}}{8 D^{3} n}
$$

Wei Hu [10] used the arc helical spring curve equation considering the periodic variation of the spiral angle of the curved spring, and derived the more accurate angular stiffness formula of the arc helical spring curve:

$$
K_{A-C}=\frac{G d^{4} R^{2}}{8 D^{3} n} \frac{(1+\mu) r^{2}+16 m^{2} R^{2}}{(1+\mu) \sqrt{r^{2}+16 m^{2} R^{2}}} \frac{1}{\sqrt{r^{2}+m^{2} R^{2}}},
$$

where: $m$ is mass of the spring; $\mu$ means Poisson's ratio; $r$ equals to half of $\mathrm{D}$.

3) Cylindrical helical elliptical section spring subjected to axial load.

Since the elliptical helical spring is better than the circular-section in the uniform of stress, it is also significant to get the formula for elliptical helical spring, Nagaya [13] obtained the stiffness calculation formula of elliptical helical spring by drawing an analogy method of cylindrical helical spring:

$$
K_{C-E}=\frac{G a^{3} b^{3}}{2 n\left(a^{2}+b^{2}\right) r^{3}},
$$

where: $a$ is the semi-major axis dimension of the elliptical section; $b$ is the semi-minor axis dimension of the elliptical section.

Li Chen [16] introduced the advanced technology of design and manufacture of elliptical cross-section helical springs, and recommend the design flow of cylindrical elliptical helical springs and a new formula. Expressive form for practical design applications is:

$$
K_{C-E}=\frac{\xi G d_{e}^{4}}{8 n D_{g}{ }^{3}}
$$

where: $\xi$ is the correction factor, $\xi=2 r^{\prime} /\left(r^{\prime 2}+1\right) ; r^{\prime}$ is the length of the spring wire section, $r^{\prime}=a / b ; d_{e}$ is the equivalent circular cross-sectional diameter of the elliptical section, and $d_{e}=2 \sqrt{a b}, D_{g}$ is the diameter of the wire center of gravity. When using the inner diameter or the outer diameter as the reference, $D_{g}=D-d+2 a$, when based on the center of gravity, $D_{g}=D$.

Till now, there are not any studies focus on researching for the stiffness of arc elliptical helical cross-section springs. This paper pays mainly work to arc elliptical spring's stiffness.

2.2. Verification of cylindrical and arc circular-section helical springs by FEA

Firstly, the spring model established was shown in Fig. 1, the parameters of the spring studied was given by Table 1.

Table 1

The geometry parameters of springs

\begin{tabular}{|c|c|c|c|c|c|}
\hline No. & $C=D / d$ & $d, \mathrm{~mm}$ & $D, \mathrm{~mm}$ & $n$ & $\alpha,^{\circ}$ \\
\hline 1 & 2.1 & 7 & 14.75 & 55 & 9 \\
\hline 2 & 2.4 & 6.125 & 14.75 & 55 & 9 \\
\hline 3 & 3.5 & 4.25 & 14.75 & 55 & 9 \\
\hline 4 & 5 & 0.5 & 2.5 & 55 & 9 \\
\hline 5 & 6.2 & 2.375 & 14.75 & 55 & 9 \\
\hline
\end{tabular}

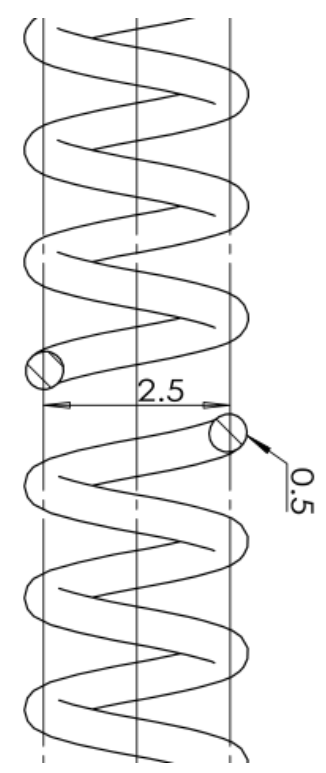

Fig. 1 The model of cylindrical helical $\operatorname{spring}(C=4)$

The current material 55CrVA of the valve spring is selected, the material density $\rho$ is $7850 \mathrm{~kg} / \mathrm{m}^{3}$, and the Young's modulus $E$ is $2.06 \times 10^{11} \mathrm{~Pa}$, Poisson's ratio $\mu$ is 0.29 . The boundary condition of the analysis step is defined as 'mechanics: displacement / corner' [11]. As shown in Fig.2, two coupling points are provided at both ends of the spring along the spring axis, respectively coupled to the end sections of the ends of the spring. One of the coupling points is 
completely fixed and axial load is applied to the other coupling point to ensure that the spring only generate small deformation. The Eight-node hexahedron element was used to mesh the spring as shown in Fig.3. When $\mathrm{C}$ is 5, the computation results of the displacement cloud chart was shown in Fig. 4.
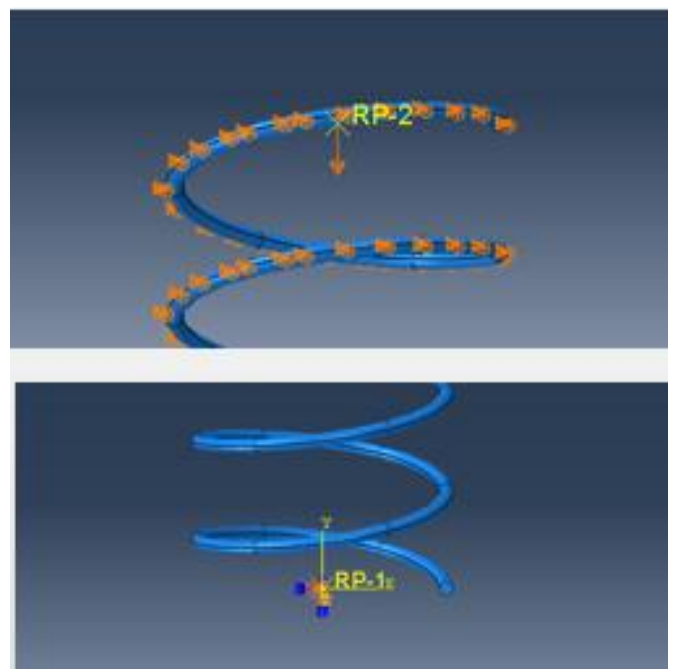

Fig. 2 The constraint and load conditions

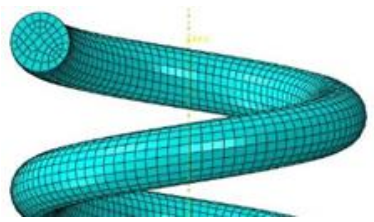

Fig. 3 The schematic diagram of mesh generation

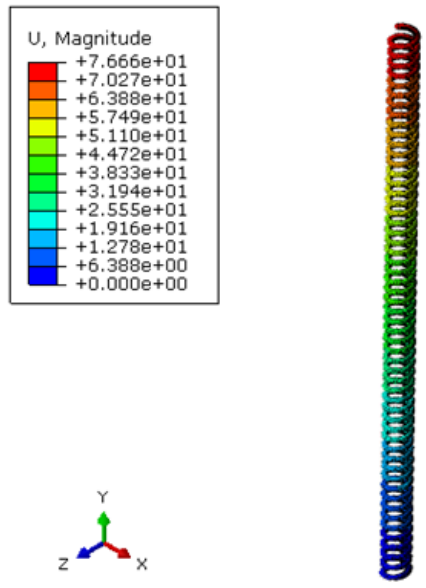

Fig. 4 The displacement cloud chart of cylindrical helical spring

The comparison between the finite element and the Wahl formula (1) was shown in Fig. 5. The maximum error of finite element is $6.57 \%$ which means that Finite Element results show good agreement with the analysis results. Wahl's formula is used widely because of its small error. But it can use only for cylindrical helical spring. We intended using finite element method to compare these two methods, and extend FAE to other arc helical spring. There is a $6.57 \%$ error in the results of FAE method compared to Wahl's formula. The errors exist in these aspects, like modeling and constraints methods, and griddling size, on which computation time depends largely. The result shows that cylindrical helical spring simulation technology applied in this paper is acceptable. The simulation technique can be used to further study the stiffness characteristics of elliptical cylindrical helical springs.

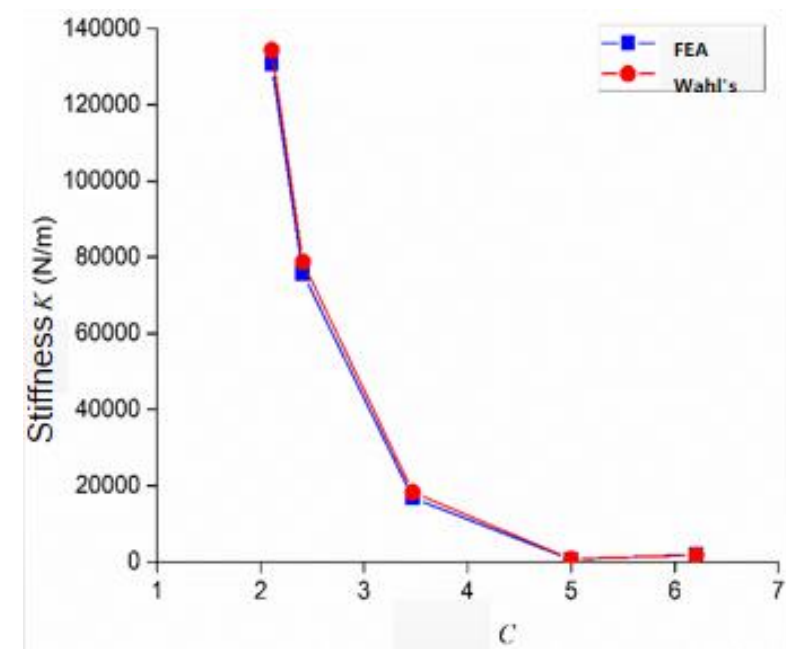

Fig. 5 The comparison between simulation and Wahl's formula

Then the stiffness achieved from FEA of arc circular-section helical spring was compared with analysis results. The arc circular-section helical spring entity and the spiral line extracted were scanned out. Advantage is that the spring axis distribution angle will not be limited, and it is suitable for a variety of opposite-shaped steel wire arc circular crosssection (elliptical cross-section will be discussed later) helical spring shape.

The main geometric parameters of the arc helical spring as shown in Table 2: spring wire diameter $d=5.2 \mathrm{~mm}$, spring diameter $D=21.5 \mathrm{~mm}$, effective number of turns $n=$ 54 , arc spring axis distribution radius $R=127.5 \mathrm{~mm}$, the arc angle $\phi=160^{\circ}$. The specific modeling was as follows [10].

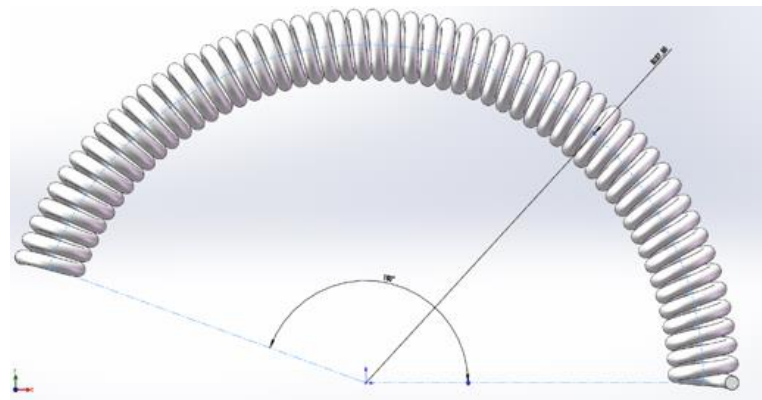

Fig. 6 The model of arc helical spring

In order to obtain a regular grid, sweeping mesh division was used in consideration of the structural characteristics of the spring, the result was shown in Fig. 7.

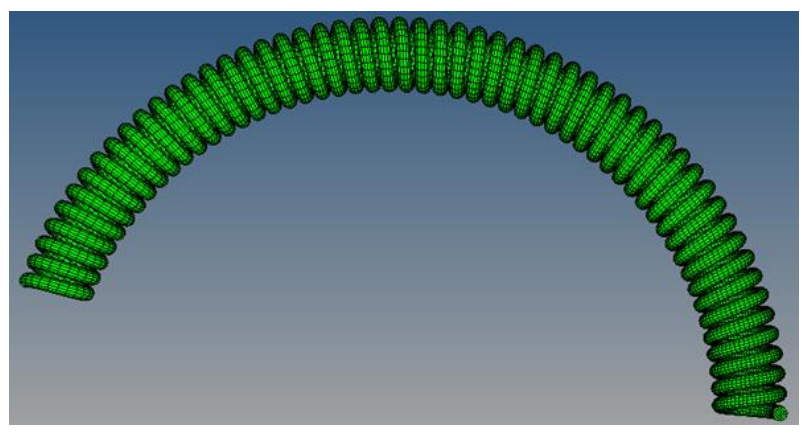

Fig. 7 The arc spring meshes 
The geometry parameters of springs

\begin{tabular}{|c|c|c|c|c|c|c|}
\hline No. & $C=D / d$ & $d, \mathrm{~mm}$ & $D, \mathrm{~mm}$ & $n$ & $R, \mathrm{~mm}$ & $\Phi,^{\circ}$ \\
\hline 1 & 3.8 & 5.2 & 20 & 54 & 127.5 & 160 \\
\hline 2 & 4.1 & 5.2 & 21.5 & 54 & 127.5 & 160 \\
\hline 3 & 4.5 & 4.4 & 20 & 50 & 114 & 160 \\
\hline
\end{tabular}

Considering the structure and working principle of the Dual Mass Flywheel, it is found that the arc helical spring is constrained to the spring chamber named annular groove which has the coaxial line, when the spring is working and slightly deformed, due to the groove position restriction, its deformation mainly occurs in the direction of the axis. As shown in Fig. 8, when the spring is slightly deformed, there are four main constraints of the spring: the left end of the spring is completely fixed and the right end is constrained to move and rotate in the $\mathrm{X}$ and $\mathrm{Z}$ directions, is also loaded the angular displacement whose value was 0.1 $\mathrm{rad}$, and the vertical direction of the spring restricts the movement and rotation in the $\mathrm{Y}$ and $\mathrm{Z}$ directions. The spring as a whole constrains the movement in the $Z$ direction. The right end of the spring is the loading surface, and the Y-direction pressure $F$ is applied at the middle diameter to ensure that the spring only has a small deformation.

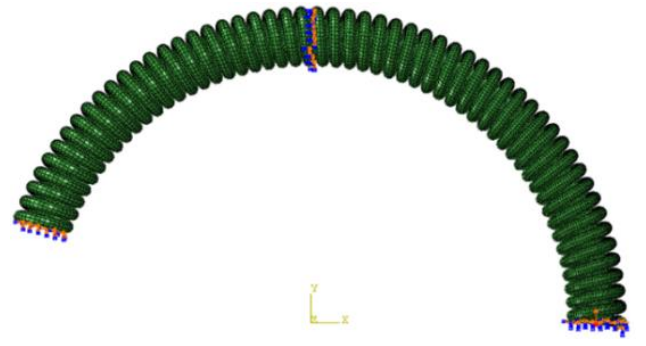

Fig. 8 The constraint and load conditions

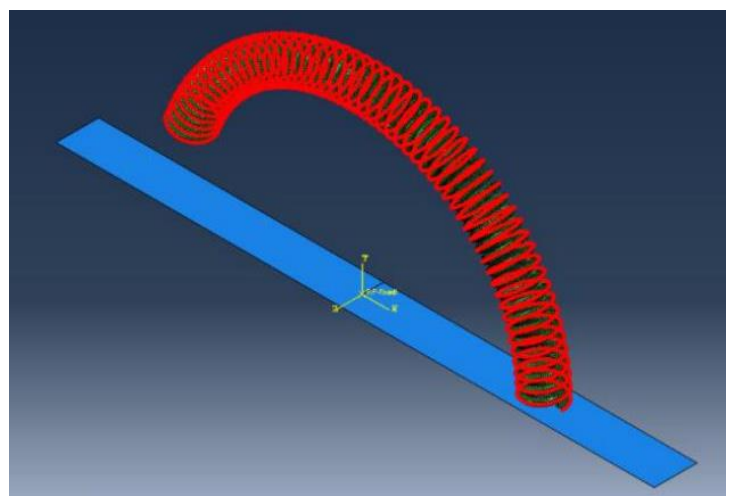

Fig. 9 The displacement cloud map of $\operatorname{arc} \operatorname{spring}(C=4.1)$

The parameters mentioned above were carried over into formula (5) to get the calculation results. And simulation results were put in formula $F \times R /(\max / R)$ then acheived the value $K_{A-C}=271.6 \mathrm{Nm} / \mathrm{rad}$.

\subsection{Study on stiffness of arc elliptical helical springs}

This section draws on the research of elliptical cylindrical helical spring stiffness. Based on the mechanical analysis of the elliptical cross-section spiral spring, the regression formula and the finite element analysis are used to obtain the stiffness regression formula.

According to reference [16] and stiffness formulae mentioned above, there are several factors have vital impact on the stiffness, hence in the primary regression design, the regression formula of the springs' stiffness was constructed as follows:

$$
K_{A-E}=\frac{e^{\alpha_{0}} a^{\alpha_{1}} b^{\alpha_{2}} R^{\alpha_{3}}}{D^{\alpha_{4}} n^{\alpha_{5}}\left(a^{2}+b^{2}\right)^{\alpha_{6}}}
$$

where: $\alpha_{k}$ is the constant would be calculated. $k=1,2, \ldots . .6$. $b=a / r$ ', formula (8) can transform as:

$$
\begin{aligned}
& \ln K_{A-E}=\beta_{0}+\beta_{1} \ln a+\beta_{2} \ln r^{\prime}+\beta_{3} \ln \left(1+r^{\prime 2}\right)+ \\
& +\beta_{4} \ln D+\beta_{5} \ln n+\beta_{6} \ln R
\end{aligned}
$$

Let $\ln K_{A-E}$ be the response variable of $y, \ln a, \ln r^{\prime}$, $\ln \left(1+r^{\prime 2}\right), \ln D, \ln n, \ln R$ are the factors $x_{1}, x_{2}, x_{3}, x_{4}, x_{5}, x_{6}$ respectively. The orthogonal regression design steps are as follows:

\subsubsection{Encoding the value of the factors}

According to the actual production application, the long semi-axis length a of the arc elliptical section helical spring is $1.2 \sim 2.2 \mathrm{~mm}$, and the ratio of long and short axis $\mathrm{r}^{\prime}$ is in the range of $1 \sim 1.5$. The spring diameter $D$ ranges from 20 to $30 \mathrm{~mm}$. The effective number of turns $\mathrm{n}$ ranges from 50 to 85 , and the spring axis distribution radius $R$ ranges from 114 to $145 \mathrm{~mm}$. The factors are encoded by Eq. (10). The range of factors and the encoding of each factors are shown in Table 3 and factors corresponding to the actual numerical value shown in Tables 4 and 5 .

$$
\left\{\begin{array}{l}
x_{0 j}=\left(x_{1 j}+x_{2 j}\right) / 2 \\
\Delta_{j}=\left(x_{2 j}-x_{1 j}\right) / 2 \\
z_{j}=\left(x_{j}-x_{0 j}\right) / \Delta_{j}
\end{array}\right.
$$

Table 3

Factors corresponding to the actual numerical value

\begin{tabular}{|c|c|c|c|c|c|}
\hline$x_{j}\left(z_{j}\right)$ & $x_{1}, \mathrm{~mm}$ & $x_{2}$ & $x_{3}, \mathrm{~mm}$ & $x_{4}$ & $x_{5}, \mathrm{~mm}$ \\
\hline$x_{1 j}(-1)$ & 0.1823 & 0 & 2.9957 & 3.9120 & 4.7362 \\
\hline$x_{2 j}(+1)$ & 0.7885 & 0.4055 & 3.4012 & 4.4427 & 4.9767 \\
\hline$x_{0 j}(0)$ & 0.4854 & 0.2027 & 3.1985 & 4.1773 & 4.8565 \\
\hline$\Delta_{j}$ & 0.3031 & 0.2027 & 0.2027 & 0.2653 & 0.1203 \\
\hline
\end{tabular}

2.3.2 Test (simulation) plan and results

Test plan

Table 4

$$
\text { Test plan }
$$

\begin{tabular}{|c|c|c|c|c|c|}
\hline \multicolumn{6}{|c|}{ The test program expressed in code values and test results } \\
\hline No. & $z 1$ & $z 2$ & $z 3$ & $z 4$ & $z 5$ \\
\hline 1 & 1 & 1 & 1 & 1 & 1 \\
\hline 2 & 1 & 1 & 1 & -1 & -1 \\
\hline 3 & 1 & -1 & -1 & 1 & 1 \\
\hline 4 & 1 & -1 & -1 & -1 & -1 \\
\hline 5 & -1 & 1 & -1 & 1 & -1 \\
\hline 6 & -1 & 1 & -1 & -1 & 1 \\
\hline 7 & -1 & -1 & 1 & 1 & -1 \\
\hline 8 & -1 & -1 & 1 & -1 & 1 \\
\hline 9 & 0 & 0 & 0 & 0 & 0 \\
\hline
\end{tabular}


Table 5

Table of regression formula

\begin{tabular}{|c|c|c|c|c|c|c|c|}
\hline \multicolumn{7}{|c|}{ Regression formula } \\
\hline No. & $x 1$ & $x 2$ & $x 3$ & $x 4$ & $x 5$ & $x 6$ & $y$ \\
\hline 1 & 0.78845736 & 0.405465108 & 3.401197382 & 4.442651256 & 4.976733742 & 1.178654996 & 12.98641137 \\
\hline 2 & 0.78845736 & 0.405465108 & 3.401197382 & 3.912023005 & 4.736198448 & 1.178654996 & 17.51010509 \\
\hline 3 & 0.78845736 & 0 & 2.995732274 & 4.442651256 & 4.976733742 & 0.693147181 & 71.3437394 \\
\hline 4 & 0.78845736 & 0 & 2.995732274 & 3.912023005 & 4.736198448 & 0.693147181 & 104.5534996 \\
\hline 5 & 0.182321557 & 0.405465108 & 2.995732274 & 4.442651256 & 4.736198448 & 1.178654996 & 2.086035313 \\
\hline 6 & 0.182321557 & 0.405465108 & 2.995732274 & 3.912023005 & 4.976733742 & 1.178654996 & 4.272071523 \\
\hline 7 & 0.182321557 & 0 & 3.401197382 & 4.442651256 & 4.736198448 & 0.693147181 & 2.32694718 \\
\hline 8 & 0.182321557 & 0 & 3.401197382 & 3.912023005 & 4.976733742 & 0.693147181 & 4.877058687 \\
\hline 9 & 0.485384731 & 0.202695916 & 3.198501674 & 4.177299947 & 4.856499947 & 0.916246767 & 11.02809819 \\
\hline
\end{tabular}

Linear regression analysis was performed using the SPSS software with the Stepwise method, and the multiple correlation coefficient Table 6 , the variance analysis Table 7 , and the regression coefficient test Table 8 were obtained.

Table 6

Multiple correlation coefficients table

\begin{tabular}{|c|c|c|c|}
\hline $\begin{array}{c}\text { Complex correla- } \\
\text { tion coefficient } R\end{array}$ & $\begin{array}{c}\text { Decisive coef- } \\
\text { ficient } R^{2}\end{array}$ & Adjustment $R^{2}$ & $\begin{array}{c}\text { Standard es- } \\
\text { timated error }\end{array}$ \\
\hline 1.000 & 0.997 & 0.978 & 0.17683 \\
\hline
\end{tabular}

Table 7

Analysis of variance table

\begin{tabular}{|c|c|c|c|c|c|}
\hline Model & $\begin{array}{c}\text { Quadratic } \\
\text { sum SS }\end{array}$ & $\begin{array}{c}\text { DOF } \\
\text { df }\end{array}$ & $\begin{array}{c}\text { Mean } \\
\text { square MS }\end{array}$ & $F$ & Sig. \\
\hline Regression $R$ & 11.213 & 6 & 1.87 & 59.787 & 0.017 \\
\hline Residual $E$ & 0.063 & 2 & 0.031 & - & - \\
\hline Total $T$ & 11.284 & 8 & - & - & - \\
\hline
\end{tabular}

Table 8

The validation of regression coefficients

\begin{tabular}{|c|c|c|c|c|c|}
\hline \multirow{2}{*}{ Model } & \multicolumn{2}{|c|}{ Non-standardized coefficient } & Standard & \multirow{2}{*}{$t$} & \multirow{2}{*}{ Sig. } \\
\cline { 2 - 5 } & $B$ & Standard & Trial version & & 0.986 \\
\hline (constant) & 0.141 & 7.213 & - & 0.020 & 0.006 \\
\hline $\ln a$ & 2.571 & 0.206 & 0.656 & 12.459 & 0.556 \\
\hline $\ln r$ & -8.039 & 11.459 & -1.732 & -0.702 & 0.015 \\
\hline $\ln D$ & -2.514 & 0.308 & -0.429 & -8.150 & 0.017 \\
\hline $\ln n$ & -1.766 & 0.236 & -0.394 & -7.492 & 0.030 \\
\hline $\ln R$ & 2.953 & 0.520 & 0.299 & 5.680 & 0.658 \\
\hline
\end{tabular}

Considering that the factor $\ln r$ ' have close correspondence with $\ln \left(1+r^{\prime 2}\right)$ and Sig. of $\ln \left(1+r^{\prime 2}\right)$ has bigger value than the others, the factor $\ln \left(1+r^{\prime 2}\right)$ was finally eliminated, the regression design experiment was proceeded again, coefficient of Table 9, the variance analysis of Table 10 , and the regression coefficient test of Table 11 were obtained.

It can be seen from Table 9 that adjusted $R^{2}$ is 0.983 . From Table 10, the Sig. is 0.002 , which indicated that the dependent variable represented by the regression equation has a very significant relationship with the independent variable. From Table 11, it can be found that $\ln a, \ln D, \ln r ', \ln n$, and $\ln R^{2}$ have Sig. $\leq 0.01$, shear modulus $G$ was contained in constant value, resulted in Sig. of the constant value expressed bigger than others. The values proved the model established is effective. Hence the stiffness formula was as follows:

$\ln K_{A-E}=3.542+2.571 \ln a-2.146 \ln r^{\prime}-$

$$
-2.514 \ln D-1.766 \ln n+2.953 \ln R \text {. }
$$

Formula (11) is be rounded and transformed as:

$$
K_{A-E}=\frac{4.33 \times 10^{-10} G a^{2.6} R^{3}}{r^{\prime 2} D^{2.6} n^{1.766}}
$$

Table 9

Multiple correlation coefficients table

\begin{tabular}{|c|c|c|c|}
\hline $\begin{array}{c}\text { Complex correla- } \\
\text { tion coefficient } R\end{array}$ & $\begin{array}{c}\text { Decisive co- } \\
\text { efficient } R^{2}\end{array}$ & $\begin{array}{c}\text { Adjustment } \\
R^{2}\end{array}$ & $\begin{array}{c}\text { Standard esti- } \\
\text { mated error }\end{array}$ \\
\hline 1.000 & 0.997 & 0.983 & 0.15367 \\
\hline
\end{tabular}

Table 10

Analysis of variance table

\begin{tabular}{|c|c|c|c|c|c|}
\hline Model & $\begin{array}{c}\text { Quadratic } \\
\text { sum SS }\end{array}$ & DOF df & $\begin{array}{c}\text { Mean square } \\
\text { MS }\end{array}$ & $F$ & Sig. \\
\hline Regression $R$ & 11.213 & 5 & 2.243 & 94.970 & 0.02 \\
\hline Residual $E$ & 0.063 & 3 & 0.024 & - & - \\
\hline Total $T$ & 11.284 & 8 & - & - & - \\
\hline
\end{tabular}

Putting the parameters of the arc circular section into (12), it seems that the elliptical stiffness formula degenerated to the circular-section stiffness formula, regression formula (12) has small error and the result of Table 12 was shown as follows. Wei $\mathrm{Hu}$ [10] tested the torque in small 
torsion angle range in $0-12^{\circ}$ with two same size and material springs, got the torque as $455.99 \mathrm{Nm} / \mathrm{rad}$.

Table 11

The validation of regression coefficients

\begin{tabular}{|c|c|c|c|c|c|}
\hline \multirow{2}{*}{ Model } & \multicolumn{2}{|c|}{ Non-standardized coefficient } & Standard & \multirow{2}{*}{$t$} & \multirow{2}{*}{ Sig. } \\
\cline { 2 - 4 } & $B$ & Standard & Trial version & & 0.253 \\
\hline (constant) & 3.542 & 2.509 & - & 1.412 & 0.001 \\
\hline $\ln a$ & 2.571 & 0.179 & 0.656 & 14.339 & 0.004 \\
\hline $\ln r^{\prime}$ & -2.146 & 0.268 & -0.366 & -8.010 & 0.003 \\
\hline $\ln D$ & -2.514 & 0.268 & -0.429 & -9.380 & 0.003 \\
\hline $\ln n$ & -1.766 & 0.205 & -0.394 & -8.623 & 0.007 \\
\hline $\ln R$ & 2.953 & 0.452 & 0.299 & 6.537 & \\
\hline
\end{tabular}

Table 12

Results comparison $(C=4.1)$

\begin{tabular}{|c|c|c|c|c|}
\hline Method & Experiment & FEA & $\begin{array}{c}\text { Reference [16] } \\
\text { stiffness }\end{array}$ & $\begin{array}{c}\text { Regression } \\
\text { formula (12) }\end{array}$ \\
\hline $\begin{array}{c}K_{T}, \\
\text { Nm/rad }\end{array}$ & $227.995^{[10]}$ & 272.6 & 217.03 & 252.91 \\
\hline Error, \% & - & $19.56 \%$ & $4.8 \%$ & $10.9 \%$ \\
\hline
\end{tabular}

Table 13

Formula (12) results compared with formula (5)

\begin{tabular}{|c|c|c|c|c|}
\hline No. & $C=D / d$ & $\begin{array}{c}\text { Formula (5), } \\
\mathrm{N} \cdot \mathrm{m} / \mathrm{rad}\end{array}$ & $\begin{array}{c}\text { Formula (12), } \\
\mathrm{N} \cdot \mathrm{m} / \mathrm{rad}\end{array}$ & Error \\
\hline 1 & 3.8 & 271.698 & 305.11 & $12.25 \%$ \\
\hline 2 & 4.1 & 218.707 & 252.91 & $15.63 \%$ \\
\hline 3 & 4.5 & 120.253 & 132.557 & $10.23 \%$ \\
\hline
\end{tabular}

According to Table 13 , error $15.63 \%$ is calculated by comparing formula (12) we derived with the existed formula (5) when $C$ is 4.1 . This similar method is verified its correctness by using the steps above to research cylindrical elliptical cross-section helical springs, and get stiffness formula of the spring as follows:

$$
\begin{aligned}
& \ln K_{C-E}=19.556+4.020 \ln a-1.052 \ln r^{\prime}- \\
& -0.954 \ln \left(1+r^{\prime 2}\right)-3.020 \ln D-1.006 \ln n
\end{aligned}
$$

In order to facilitate engineering application, the regression formula (13) is being rounded to obtain the stiffness formula of elliptical cylindrical helical spring:

$$
K_{C-E}=\frac{152.59 \times 10^{-5} G a^{3} b^{3}}{D^{3} n\left(a^{2}+b^{2}\right)},
$$

where: $N / m$ is unit of $K$, rather $a, b$ and $D$ are in mm.

To further verify the accuracy of the regression equation, it compared the finite element simulation with the regression formula (14), the results is shown in Fig.12. The results show that the average error of the regression formula (14) is $2.31 \%$ compared with the finite element simulation results.

As shown in Table 14, the finite element simulation error is $4.19 \%$ compared with the circular cross-section cylindrical helical spring test. The accuracy of both formulas meets the requirements and can be used to guide the design and selection of springs. The regression formula (14) has an error of only $2.31 \%$ and the highest precision. It shows that the regression design combined with the ABAQUS finite element analysis method to study the spring stiffness has feasibility and practical application value. The experiment focus on stiffness of cylindrical elliptical cross-section helical springs proved the regression method is available for researching the arc helical springs' stiffness.

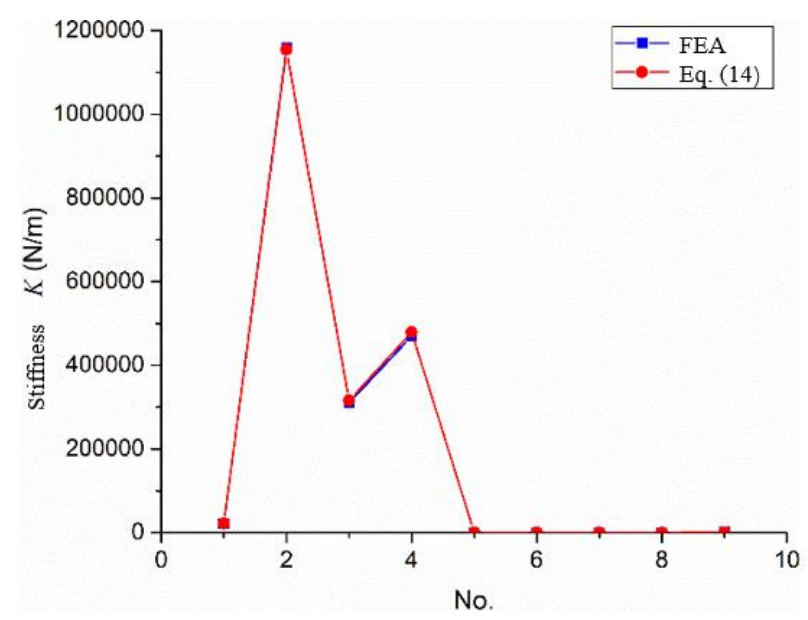

Fig. 10 The comparison between simulation and regression formula

Table 14

The comparison of experiment results, simulation results and formulas calculation results

\begin{tabular}{|c|c|c|c|}
\hline Method & Experiment & FEA & Formula (14) \\
\hline Stiffness, N/m & $22403^{[3]}$ & 21463.415 & 21463.415 \\
\hline Error, \% & - & 4.19 & 2.31 \\
\hline
\end{tabular}

\section{Results and discussion}

In this paper, the research status of the helical spring stiffness of circular section and elliptical section are summarized. The method of finite element simulation and regression design is employed to study the stiffness of elliptical section helical spring. The main research results are as follows:

By comparing the results of finite element and formula (1), the maximum error of finite element is $6.57 \%$. The accuracy of cylindrical helical spring simulation technology is verified. The simulation technique can be used to deeply study the stiffness characteristics of elliptical cylindrical helical springs.

The mechanical theory of the cylindrical elliptical cross section helical spring is analyzed to obtain the stiffness theoretical formula, and the experimental error is $2.31 \%$. The stiffness characteristics of cylindrical elliptical helical 
springs are studied by the combination of experimental design of regression and finite element simulation. The improved linear regression design successfully obtains the stiffness formula (14). At the same time, it is proved that the regression design combined with Finite Element Analysis method to study the spring stiffness is feasible and practical. The modeling methods of arc helical springs are introduced. The overall scheme of finite element simulation technology of arc helical springs based on ABAQUS is proposed.

Based on the elastic analysis method of circular arc-shaped helical spring, the elliptical arc-shaped helical spring stiffness model is derived. A combination method of orthogonal regression design and finite element simulation is used to obtain an elliptical arc-shaped helical. The spring stiffness formula is of great significance for the wide application of elliptical cross-section spiral springs. The accuracy of the arc helical springs simulation technique is verified by comparison with the test results and the existing curved spring stiffness formula (5). The results showed that the finite element error is less than $15 \%$, error seems a little bigger than cylindrical springs because diameters of cross section are inadequately accorded with the stiffness $K_{A-E}$ required. The simulation technique can be used to study the stiffness characteristics of elliptical arc-shaped helical springs.

Finite Element Analysis method is used for researching the arc helical springs' stiffness value of arc circular-section, the difficulty is that there isn't a specific requirement describing which type of forces to exert when loading the constraints to the spring, indirectly it leads that FEA result has bigger error combined with the formula (5). It's urgent to acknowledge the forces and constraints occurred in spring chamber of Dual Mass Flywheel when the spring working.

Although the stiffness characteristics of elliptical cross-section spiral springs is studied and the stiffness formula is obtained, there is no relevant experimental data of elliptical cross-section helical springs for doing more analysis with the stiffness formula. The stiffness formula obtained by regression needs further optimization. In order to improve its universality and calculation accuracy, better design method for optimization of the arc elliptical cross-section helical spring should be carried out.

\section{Conclusion}

In this paper, a method combined the linear regression experimental design with Finite Element Analysis is issued to study the stiffness of the arc elliptical helical springs was used. A formula for $K_{A-E}$ was achieved with some key factors that have great impacts on the spring. Thus, formula is verified with the $K_{A-C}$, and have a quite good agreement, which means this formula can be used to predict the correctness of stiffness formula $K_{A-E}$ Based on the principle that a circle is the special form of ellipse, the stiffness formula got has certain correctness. More experiments should be carried out to test stiffness of arc elliptical springs to get the stiffness data, and will verify the formula by parameters of arc elliptical springs then compare with the data.

\section{References}

1. Shengwen Deng.; Maoru Chi.; Chaotao Liu. 2016.
Study on static and dynamic characteristics of metal helical spring, Computer Science and Electronic Technology International Society: 5.

2. Theodossiades, S.; Gnanakumarr, M.; Rahnejat, H.; Kelly, P. 2006. Effect of a dual-mass flywheel on the impact-induced noise in vehicular powertrain systems, Journal of Automobile Engineering 220:747-761. http://dx.doi.org/10.1243/09544070JAUTO55.

3. Gzal, M.; Groper, M.; Gendelman, O. 2017. Analytical, experimental and finite element analysis of elliptical cross-section helical spring with small helix angle under static load, International Journal of Mechanical Sciences 130: 476-486. http://dx.doi.org/10.1243/10.1016/j.ijmecsci.2017.06.25.

4. Nagaya, K.; Hirata, Y.; Tsurumi, T.; Takeda, S.; Nagai, K.; Tanifuji, K. 1991. Design formulae for elliptical cross-section helical springs, Japan Society of Spring Engineers 57: 283-287. http://dx.doi.org/10.1299/kikaic.57.283.

5. Schaper, U.; Sawodny, O.; Mahl, T. 2009. Modeling and torque estimation of an automotive dual mass flywheel, American Control Conference: 1207-1217.

6. Zhao, G. M.; Jiang, Z. F.; Chen, L. 2012. Research and experimental verification on damping characteristics of circumferential arc spring dual mass flywheel, Chinese Internal Combustion Engine Engineering 33(1): 81-86. http://dx.doi.org/10.13949/j.cnki.nrjgc.2012.01.007.

7. Xun Zhu.; Chengli Song.; Gaohui Zhao. 2015. Study on the influence of cylinder helical spring's geometrical parameters on spring constant based on ABAQUS, Journal of Machine Design \& Research 31(4): 95-98. http://dx.doi.org/10.13952/j.cnki.jofmdr.2015.0149.

8. Demin Chen.; Yueyin Ma.; Sun W.; Xiaolin Guo.; Xiaofei Shi. 2011. Research of design and vibration reduction of dual mass flywheel with arc helix spring, Electronic \& Mechanical Engineering \& Information Technology International Conference 5: 2706 - 2709. http://dx.doi.org/doi:10.1109/EMEIT.2011.6023026.

9. Wu, C.; Peng, Y.; Xiang, C. 2014. Static torsional stiffness computation of circumferential arc spring dual mass flywheel, Advanced Materials Research 1065-1069. http://dx.doi.org/10.4028/AMR.1065-1069.2080.

10. Wei Hu.; Zhengfeng Jiang.; Rong Zeng. 2014. Study on static stiffness model of long circumferential spring dual mass flywheel, Journal of Chinese Mechanical Engineering 24: 3278-3288. http://dx.doi.org/10.3969/j.issn.1004-132X.2014.24.003.

11. Mohazzabi, P.; Mccrickard, J. P. 1989. On the spring constant of a close-coiled helical spring, American Journal of Physics 57,7:639-641. http://dx.doi.org/10.1119/1.15962.

12. Vebil Yıldırım. 2016. Exact determination of the global tip deflection of both close-coiled and open-coiled cylindrical helical compression springs having arbitrary doubly-symmetric cross-sections, International Journal of Mechanical Sciences 115: 280-298. http://dx.doi.org/10.1016/j.ijmecsci.2016.06.022.

13. Nagaya, K.; Hirata, Y.; Tsurumi, T. 1991. Design formulae for elliptical-cross-section helical springs, Transactions of the Japan Society of Mechanical Engineers C 57,533:283-287. http://dx.doi.org/10.1115/1.2917058.

14. Wahl, A. M. 1963. Mechanical springs. 
15. Tao Chen.; Zhenhua Lv.; Chengqian Su. 2006. Analysis method for elastic characteristics of arc spring, Journal of Chinese Mechanical Engineering 05: 57-59.

http://dx.doi.org/10.3321/j.issn:1004-132X.2006.05.15.

16. Li Chen. 2013. Design and production of ellipse or oval steel wire high stress helical spring, Journal of Metal Product 39(5) :23-29.

http://dx.doi.org/10.3969/j.issn.1003-4226.2013.05.007.

Y. Wang, Q. Wang, Z. Su

\section{NUMERICAL STUDIES ON THE STIFFNESS OF ARC ELLIPTICAL CROSS-SECTION HELICAL SPRING SUBJECTED TO CIRCUMFERENCE FORCE}

\section{S u m m a r y}

Due to its excellent properties, elliptical cross-section helical spring has been widely used in automobile industry, such as valve spring, arc spring used in Dual Mass Flywheel and so on. Existing stiffness formulae of helical spring remain to be tested, and stiffness property of elliptical cross-section arc spring has been little studied. Hence, study on the stiffness of elliptical cross-section helical spring is significant in the development of elliptical cross-section helical spring. This paper proposes a method to study the stiffness property of elliptical cross-section helical spring that the experiment design method is adopted with finite element analysis. Firstly, the finite element analysis method was used to verify the cylindrical (circular cross-section and elliptical cross-section) springs. Then, the regression formula was designed and derived compared with the reference springs' stiffness formulae by experimental design. Last, regression formula was verified with existing experiment data. The novelty in this paper is that simulation technology of arc spring was investigated and a stiffness regression equation of arc elliptical cross-section spring was obtained using orthogonal regression design, with significance in wide use of the arc elliptical cross-section helical spring promotion.

Keywords: arc spring, elliptical cross-section, stiffness, finite element analysis, multivariate statistical regression, experimental design.

Received January 07, 2020 Accepted August 07, 2021

This article is an Open Access article distributed under the terms and conditions of the Creative Commons Attribution 4.0 (CC BY 4.0) License (http://creativecommons.org/licenses/by/4.0/). 